Optical emission studies of nitrogen plasma generated by $\mathrm{IR} \mathrm{CO}_{2}$ laser pulses

This article has been downloaded from IOPscience. Please scroll down to see the full text article.

2007 J. Phys. B: At. Mol. Opt. Phys. 404573

(http://iopscience.iop.org/0953-4075/40/24/003)

View the table of contents for this issue, or go to the journal homepage for more

Download details:

IP Address: 161.111.22.141

The article was downloaded on 13/12/2012 at 09:38

Please note that terms and conditions apply. 


\title{
Optical emission studies of nitrogen plasma generated by IR $\mathrm{CO}_{2}$ laser pulses*
}

\author{
J J Camacho ${ }^{1}$, J M L Poyato ${ }^{1}$, L Díaz ${ }^{2}$ and M Santos ${ }^{2}$ \\ ${ }^{1}$ Departamento de Química-Física Aplicada, Facultad de Ciencias, Universidad Autónoma de \\ Madrid, Cantoblanco, 28049 Madrid, Spain \\ ${ }^{2}$ Instituto de Estructura de la Materia, CFMAC, CSIC, Serrano 121, 28006 Madrid, Spain \\ E-mail: j.j.camacho@uam.es
}

Received 12 July 2007, in final form 26 September 2007

Published 19 November 2007

Online at stacks.iop.org/JPhysB/40/4573

\begin{abstract}
Large-scale plasma produced in nitrogen gas at room temperature and pressures ranging from $4 \times 10^{3}$ to $1.2 \times 10^{5} \mathrm{~Pa}$ by high-power laserinduced dielectric breakdown (LIDB) has been investigated. Time-integrated optical nitrogen gas spectra excited from a $\mathrm{CO}_{2}$ laser have been measured and analysed. The spectrum of the generated plasma is dominated by the emission of strong $\mathrm{N}^{+}$and $\mathrm{N}$ and very weak $\mathrm{N}^{2+}$ atomic lines and molecular features of $\mathrm{N}_{2}^{+}\left(\mathrm{B}^{2} \Sigma_{\mathrm{u}}^{+}-\mathrm{X}^{2} \Sigma_{\mathrm{g}}^{+}\right), \mathrm{N}_{2}^{+}\left(\mathrm{D}^{2} \Pi_{\mathrm{g}}-\mathrm{A}^{2} \Pi_{\mathrm{u}}\right), \mathrm{N}_{2}\left(\mathrm{C}^{3} \Pi_{\mathrm{u}}-\mathrm{B}^{3} \Pi_{\mathrm{g}}\right)$ and very weak $N_{2}\left(B_{3} \Pi_{g}-A^{3} \Sigma_{u}^{+}\right)$. The relative intensities of the $0-0$ band heads in the $\mathrm{N}_{2}(\mathrm{C}-\mathrm{B})$ and $\mathrm{N}_{2}^{+}(\mathrm{B}-\mathrm{X})$ systems are very weak as compared with the chemiluminescence spectrum of nitrogen formed in a glow discharge. An excitation temperature $T_{\mathrm{exc}}=21000 \pm 1300 \mathrm{~K}$ was calculated by means of the relative intensity of ionized nitrogen atomic lines assuming local thermodynamic equilibrium. Optical breakdown threshold intensities in $\mathrm{N}_{2}$ at 9.621 $\mu \mathrm{m}$ have been determined. The physical processes leading to the LIDB of nitrogen in the power density range $0.4<J<4.5 \mathrm{GW} \mathrm{cm}^{-2}$ have been analysed. From our experimental observations we can suggest that, although the first electrons must appear via multiphoton ionization or natural ionization, electron cascade is the main mechanism responsible for the LIDB in nitrogen.
\end{abstract}

(Some figures in this article are in colour only in the electronic version)

\section{Introduction}

It is well known that gases such as $\mathrm{N}_{2}$ under normal absorption conditions are relatively transparent to laser radiation. Since nitrogen is a homonuclear diatomic molecule, the

* In Memoriam: Professor Antonio Pardo Martinez. 
vibration-rotation and pure rotation spectra are not allowed, hence $\mathrm{N}_{2}$ exhibits no infrared spectrum. However, when the laser intensity increases and reaches a certain threshold value, as happens with high-power lasers (ruby, $\mathrm{Nd}$ :YAG, $\mathrm{CO}_{2}$, iodine, $\mathrm{XeF}$ excimer, etc), they are no longer transparent. Laser-induced dielectric breakdown (LIDB) is characterized by a brilliant flash and a cracking noise. Since its discovery in the early 1970s, LIDB has been the subject of many investigations [1-5]. The two principal mechanisms involved in LIDB are multiphoton ionization (MPI) and avalanche collisionally induced ionization (electron cascade) through inverse bremsstrahlung (IB). The MPI phenomenon supposes the simultaneous absorption of many infrared photons of the same frequency by a single molecule. The IB process assumes the presence of initial free electrons that absorb energy from the intense electromagnetic field associated with the laser beam, until they have enough energy to ionize the surrounding media upon collisions. This produces other electrons which are in turn accelerated, resulting in an exponential rate of growth of the ionization process. The contributions of the MPI and IB mechanisms to the plasma formation depend on the kind of gas, pressure, pulse length, beam size of the laser, laser wavelength and laser power energy.

One of the most spectroscopically studied diatomic molecules is nitrogen. An extensive compilation and critical review of the observed electronic band systems of the $\mathrm{N}_{2}$ molecule and its ions has been reported by Lofthus and Krupenie [6]. As the principal component of the Earth's atmosphere, nitrogen plays a significant role in atmospheric phenomena including auroras and airglows. In laboratory, nitrogen is often present in gas mixtures in discharges, including various laser gas media as the $\mathrm{CO}_{2}$ laser used in these experiments.

Several groups have examined the LIDB emission from nitrogen by using different highpower lasers: iodine photodissociation laser [7], $\mathrm{CO}_{2}$ laser [8], ruby laser [9], neodymiumglass laser [10] and soft x-ray free-electron laser [11]. The LIDB nitrogen spectrum recorded by Babankova and co-workers [7] in the spectral region 300-700 $\mathrm{nm}$ is composed of one broadband formed from unresolved lines of $\mathrm{N}^{+}$and from the $v^{\prime}=0-v^{\prime \prime}=0$ electronic transition of $\mathrm{N}_{2}^{+}\left(\mathrm{B}^{2} \Sigma_{\mathrm{u}}^{+}-\mathrm{X}^{2} \Sigma_{\mathrm{g}}^{+}\right.$band system). The LIDB spectra from $\mathrm{N}_{2}$ reported by Nordstrom [8] and Hanafi et al [9] are composed of $\mathrm{N}$ and $\mathrm{N}^{+}$atomic lines without identification of any molecular emission. The LIDB studies of molecular nitrogen reported by Baravian et al [10] and Sorokin et al [11] detect several ion species $\mathrm{N}^{+}, \mathrm{N}_{2}^{+}$and $\mathrm{N}_{2}{ }^{2+}$ by ion time-of-flight spectroscopy.

In this work, optical emission spectroscopy (OES) has been used to investigate the chemical consequences of LIDB in nitrogen gas. The plasma generated is dominated by the emission of strong $\mathrm{N}^{+}$and $\mathrm{N}$ and very weak $\mathrm{N}^{2+}$ atomic lines and molecular features of $\mathrm{N}_{2}^{+}\left(\mathrm{B}^{2} \Sigma_{\mathrm{u}}^{+}-\mathrm{X}^{2} \Sigma_{\mathrm{g}}^{+}\right), \mathrm{N}_{2}^{+}\left(\mathrm{D}^{2} \Pi_{\mathrm{g}}-\mathrm{A}^{2} \Pi_{\mathrm{u}}\right), \mathrm{N}_{2}\left(\mathrm{C}^{3} \Pi_{\mathrm{u}}-\mathrm{B}^{3} \Pi_{\mathrm{g}}\right)$ and $\mathrm{N}_{2}\left(\mathrm{~B}_{3} \Pi_{\mathrm{g}}-\mathrm{A}^{3} \Sigma_{\mathrm{u}}^{+}\right)$. The most intense molecular band is $\mathrm{N}_{2}^{+}(\mathrm{B}-\mathrm{X})$. Surprisingly, the relative intensities of the $0-0$ band heads in the $\mathrm{N}_{2}(\mathrm{C}-\mathrm{B})$ and $\mathrm{N}_{2}^{+}(\mathrm{B}-\mathrm{X})$ systems are very weak. The excitation temperature was obtained by means of the relative intensity of $\mathrm{N}^{+}$lines assuming local thermodynamic equilibrium (LTE). The LIDB spectrum has been compared with the band spectrum of a nitrogen-filled Geissler tube formed in a glow discharge. This spectrum is dominated by the emission of strong molecular features $N_{2}\left(C^{3} \Pi_{u}-B^{3} \Pi_{g}\right)$ and $N_{2}\left(B_{3} \Pi_{g}-A^{3} \Sigma_{u}^{+}\right)$and weak $\mathrm{N}_{2}^{+}\left(\mathrm{B}^{2} \Sigma_{\mathrm{u}}^{+}-\mathrm{X}^{2} \Sigma_{\mathrm{g}}^{+}\right)$. The strong differences shown by both LIDB and glow discharge spectra must be connected with the different excitation mechanisms. On the other hand, the LIDB emission spectrum recorded here is rather similar, both in the excited neutral $\mathrm{N}$ fragments and $\mathrm{N}^{+}, \mathrm{N}^{2+}$ ionic fragments, to the spectrum produced by an inner-shell excitation of nitrogen $\left(1 \mathrm{~s}-\pi^{*}\right.$ at $\left.401 \mathrm{eV}\right)$ using a synchrotron radiation from the SuperACO storage ring reported by Marquette and co-workers [12]. Optical breakdown threshold intensities in $\mathrm{N}_{2}$ at $9.621 \mu \mathrm{m}$ have been determined for pressures ranging from $4 \times 10^{3}$ to $1.2 \times 10^{5} \mathrm{~Pa}$. The most important physical processes in the LIDB of nitrogen at the power density range $0.4<$ 


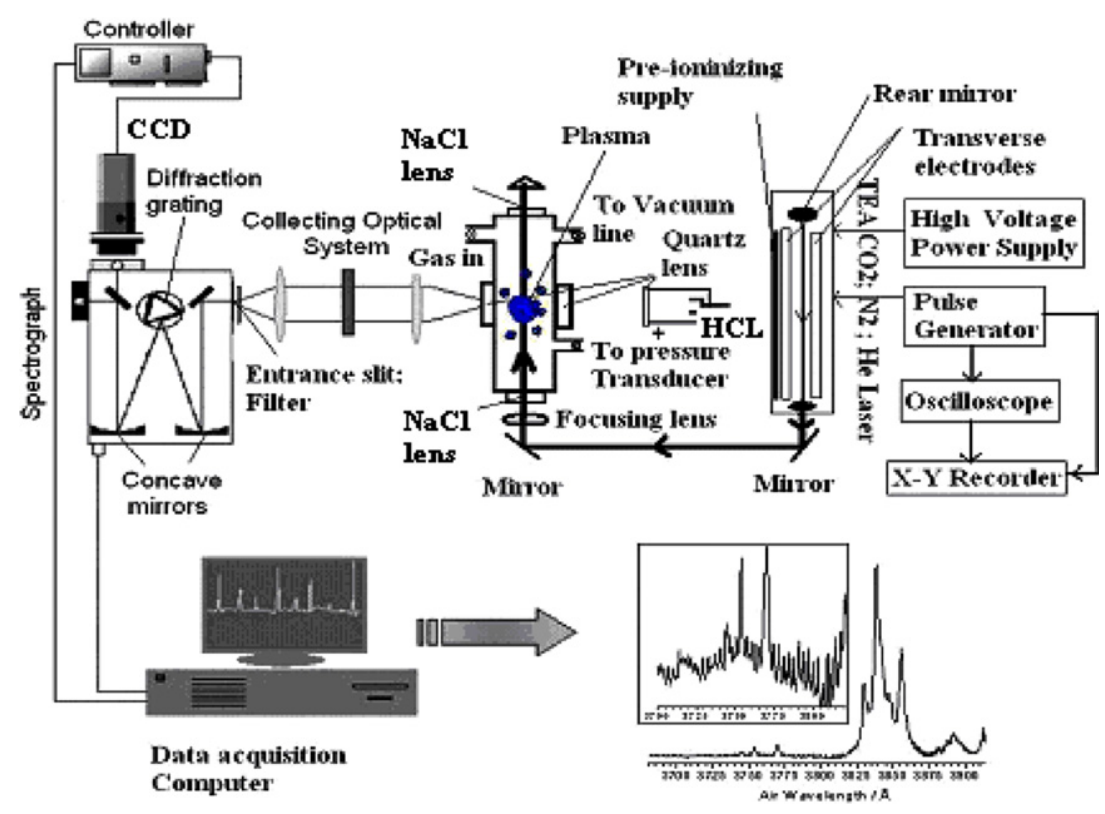

Figure 1. Schematic diagram of the experimental set-up for laser-induced breakdown.

$J<4.5 \mathrm{GW} \mathrm{cm}{ }^{-2}$ have been analysed. From our experimental observations we can propose that, although the first electrons must emerge via MPI or natural ionization, electron cascade is the most important mechanism responsible for the laser-induced breakdown in nitrogen.

\section{Experimental details}

The experimental configuration used in this work is shown in figure 1. The light source used was a Lumonics model K-103 transverse excitation atmospheric $\mathrm{CO}_{2}$ laser operating with a 8:8:84 mixture of ${ }^{12} \mathrm{CO}_{2}: \mathrm{N}_{2}: \mathrm{He}$. The laser is equipped with frontal Ge multimode optics (35\% reflectivity) and a rear diffraction grating with 135 lines $\mathrm{mm}^{-1}$ blazed at $10.6 \mu \mathrm{m}$. The $\mathrm{CO}_{2}$ laser irradiation of nitrogen was carried out using the $9 \mathrm{P}(28)$ line at $1039.36 \mathrm{~cm}^{-1}$. This wavelength was checked with a 16-A spectrum analyzer (Optical Eng. Co.). The pulse temporal profile was monitored with a photon drag detector (Rofin Sinar 7415). The pulse consisted of a spike (60 ns-FWHM) and a tail lasting approximately $3 \mu \mathrm{s}$. The optical breakdown was produced in a pyrex cell of $4.5 \mathrm{~cm}$ diameter and $43 \mathrm{~cm}$ length equipped with two $\mathrm{NaCl}$ windows for the IR laser beam orthogonal to two quartz windows for optical detection. Focused geometry was used by placing a lens $(24 \mathrm{~cm}$ focal length) in front of the cell for the $\mathrm{CO}_{2}$ laser beam. The $\mathrm{CO}_{2}$ laser fluence was calculated as the ratio of the pulse energy (measured in front of the lens with a Lumonics 20D pyroelectric detectors through a Tektronix TDS 540 digital oscilloscope) and the 1/e cross-sectional beam area (measured at the cell position with a pyroelectric array Delta Development Mark IV). In our experimental conditions, fluences of around $100 \pm 10 \mathrm{~J} \mathrm{~cm}^{-2}$ were used. Between the two measurement series, the vacuum chamber was evacuated with a rotary pump with a residual pressure of $5 \mathrm{~Pa}$. During the experiments, the chamber was filled with $\mathrm{N}_{2}$ at pressures ranging from $4 \times 10^{3}$ to $1.2 \times 10^{5} \mathrm{~Pa}$, measured by a mechanical gauge. The plasma plume was imaged by a collecting optical system onto the entrance slit of different monochromators. 

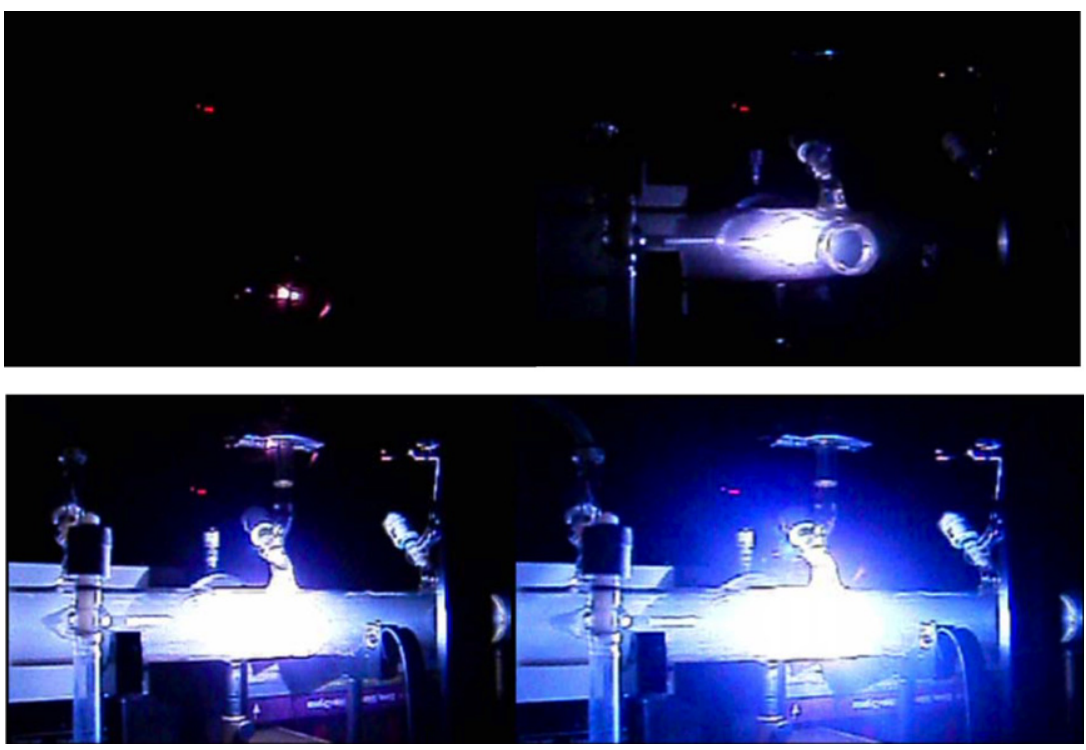

Figure 2. Four images of the laser-induced breakdown of nitrogen at atmospheric pressure at different times of the experiment.

Two spectrometers were used: ISA Jobin Yvon Spex (Model HR320) 0.32 m equipped with a plane holographic grating (2400 grooves $\mathrm{mm}^{-1}$ ) in the spectral region 2000-7500 $\AA$ at a resolution of $\sim 0.12 \AA$ in first order, and a $1 / 8 \mathrm{~m}$ Oriel spectrometer (10 and $25 \mu \mathrm{m}$ slits) with two different gratings (1200 and 2400 grooves $\mathrm{mm}^{-1}$ ) in the spectral region 2000$11000 \AA$ at a resolution of $\sim 1.3 \AA$ in first order (1200 grooves $\mathrm{mm}^{-1}$ grating). The detector was an Andor DU420-OE (open electrode) CCD (charge-coupled device) camera (1024 $\times$ 256 matrix of $26 \times 26 \mu \mathrm{m}^{2}$ individual pixels) with thermoelectric cooling working at $-30{ }^{\circ} \mathrm{C}$. The low noise level of the CCD allows long integration times and therefore the detection of very low emission intensities. The intensity response of the detection system was calibrated with a standard (Osram No 6438, 6.6 A, 200 W) halogen lamp [13] and an Hg/Ar pencil lamp [14]. An uncertainty in the experimental intensity measurements of about $10 \%$ was estimated. Several (Cu/Ne, Fe/Ne and $\mathrm{Cr} / \mathrm{Ar}$ ) hollow cathode lamps (HCL) were used for the spectral wavelength calibration of the spectrometers. The HCL lamps produce extremely narrow atomic lines with line widths around 0.01-0.02 $\AA$.

\section{Results and discussion}

\subsection{Plasma visualization}

When a sample of nitrogen is irradiated by $\mathrm{CO}_{2}$ laser lines of sufficient power, a visible breakdown occurs. Figure 2 shows a series of images of the laser-induced breakdown nitrogen plasma at different times of the experiment. A number of plasma lobes can be distinguished as well as diffuse, luminous cloud surrounding the central plasma core. Images (a)-(d) were taken at the same experimental conditions. In the images (a) and (b) only a partial breakdown is produced, while in the images (c) and (d) the breakdown is total. The LIDB spectra analysed in this work correspond to the situations described in cases (c) and (d) of figure 2. 


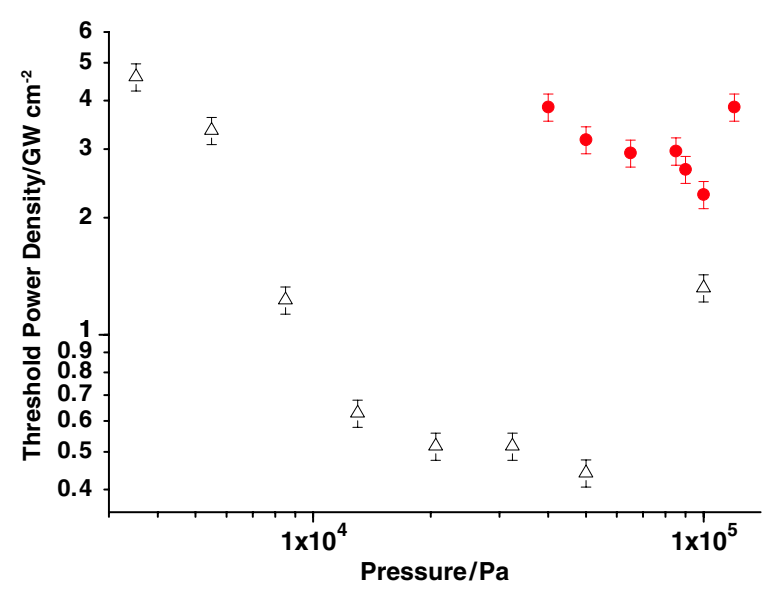

Figure 3. Threshold laser power density of the optical breakdown in nitrogen for different pressures. Solid circle: without previous breakdown; open triangle: after previous breakdown.

The observations of the LIDB geometry during the experiments indicate that the actual plasma region is not spherical, but elongated in the direction of the laser beam propagation.

\subsection{Optical breakdown threshold intensities for $\mathrm{N}_{2}$}

Several models have been proposed to describe LIDB [15-19]. From these models, the breakdown induced by the IR laser seems to be quite well explained as a collisionalassisted avalanche ionization mechanism or IB in which the development of gas breakdown is determined by the presence of some free electrons in the focal volume. It is deduced from the cited models that the procedure to do the measurements of the threshold determines the measured value. Some authors induce the breakdown at a pressure over the desired value; later the pressure is lowered and the energy is adjusted until the breakdown begins with some probability, usually around 50\% [15]. This method is similar to inducing the breakdown with energy in excess and to attenuating the laser until the spark disappears [20]. In these cases, it could be that initial free electrons have been produced by previous breakdowns and they are the seed of the avalanche process [15]. Another way to induce the breakdown is to fix the pressure and to gradually increase the energy until a visible spark is observed around the focal region at a determined number of laser pulses, 50\% [21]. In this last method, the obtained threshold value is more than $25 \%$ higher [22]. We have used both methods to measure the nitrogen breakdown at several pressures and the results are shown in figure 3. As can be seen, the behaviour of both curves is similar but, if a breakdown has been previously induced in the sample (open triangles), the pressure range to induce the breakdown is bigger and the power density is around one order of magnitude lower than when no previous breakdown is induced (solid circles). The number of free electrons is higher in conditions of previous breakdown than in the case of no previous breakdown, lowering the threshold for the plasma initiation. Also, if a sufficient concentration of electrons is generated by MPI early in the pulse so as to affect the diffusion of electrons out of the focal volume, diffusion becomes ambipolar in nature as opposed to free. In this case, the breakdown thresholds will be significantly lowered. The threshold for LIDB depends on the pressure, kind of gas, laser wavelength, pulse length, beam size and frequency of radiation. This fact can be deduced by analysing the different 


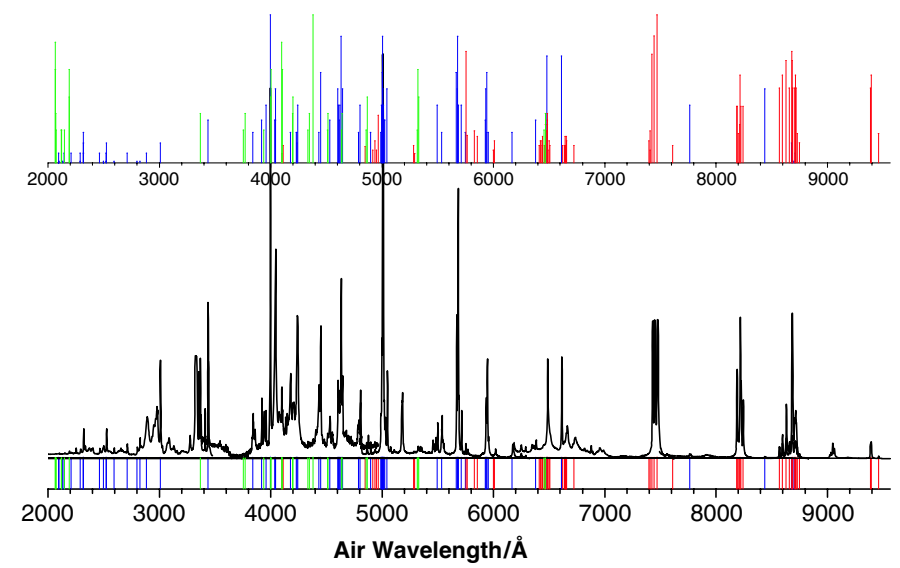

Figure 4. An overview of the LIDB emission spectrum of nitrogen at a pressure of $1.2 \times 10^{5} \mathrm{~Pa}$, excited by the $9 \mathrm{P}(28)$ line at $1039.36 \mathrm{~cm}^{-1}$ of the $\mathrm{CO}_{2}$ laser, compared with atomic lines of $\mathrm{N}, \mathrm{N}^{+}$ and $\mathrm{N}^{2+}$ (red, blue and green respectively in the online version).

values found in the literature. In the case of nitrogen, the range of threshold intensity is higher than in noble gases due to additional vibrational energy losses inherent to the nitrogen molecule [23]. Threshold intensity for $3 \times 10^{5} \mathrm{~Pa}$ of nitrogen irradiated at 530 or $350 \mathrm{~nm}$ change from $10^{12}$ to $5 \times 10^{11} \mathrm{~W} \mathrm{~cm}^{-2}$ [21], for $1.064 \mu \mathrm{m}$ and pressures between $10^{5}$ and $4.3 \times 10^{6} \mathrm{~Pa}$ the threshold intensity range between $5 \times 10^{10}$ and $2 \times 10^{11} \mathrm{~W} \mathrm{~cm}^{-2}$ [22], for $\mathrm{CO}_{2}$ lasers irradiating nitrogen in the pressures interval $2 \times 10^{4}-1.3 \times 10^{5} \mathrm{~Pa}$, power densities of $3 \times 10^{13}-2 \times 10^{14} \mathrm{~W} \mathrm{~cm}^{-2}$ were found [23]. It has to be noted that we have obtained lower threshold power densities for $\mathrm{N}_{2}$ than those given above [21-23] (figure 3). This fact can be related in part to the used focal length $(24 \mathrm{~cm})$ and beam size in the focal region $\left(7.85 \times 10^{-3} \mathrm{~cm}^{2}\right)$ that is one order of magnitude, at least, higher than the values commonly used in the literature, favouring the probability of existence of free electrons to seed the process and decreasing the threshold laser intensity due to the lack of the diffusion losses.

\subsection{Identification of the chemical species in the laser-induced nitrogen plasma}

The emission spectrum has a continuum on which the emission lines are superimposed. This continuum extends over the whole range of wavelength and has been subtracted in our spectra. It is due to the interactions between free electrons (bremsstrahlung) and to the interaction of free and bound electrons (recombination continuum). The former one is particularly important in the UV spectral region, whereas the latter one is important at longer wavelengths. Figure 4 displays an overview of the optical emission spectrum of the LIDB in nitrogen (2000-9565 $\AA$ ) compared with the atomic lines of $\mathrm{N}_{,} \mathrm{N}^{+}$and $\mathrm{N}^{2+}$ [24]. Strong atomic $\mathrm{N}^{+}$ lines dominate the spectrum but, atomic $\mathrm{N}$ lines (about three times weaker) and very weak $\mathrm{N}^{2+}$ lines (about $10^{2}-10^{3}$ times weaker) also are present. The assignments of the atomic $\mathrm{N}$ (mainly in the 5700-9565 $\AA$ spectral region), $\mathrm{N}^{+}(2000-6000 \AA)$ and $\mathrm{N}^{2+}(2000-5500 \AA)$ individual lines are indicated by stick labels. In the upper part of figure 4 , we indicate in a column graph the relative intensities of atomic observed $\mathrm{N}, \mathrm{N}^{+}$and $\mathrm{N}^{2+}$ lines tabled in the NIST Atomic Spectral Database [24-30]. There is a good agreement between line intensities tabulated in NIST and the measured intensities observed here for $\mathrm{N}, \mathrm{N}^{+}$and $\mathrm{N}^{2+}$. The spectrum of figure 4 has been obtained with six successive exposures on the CCD detector using the 

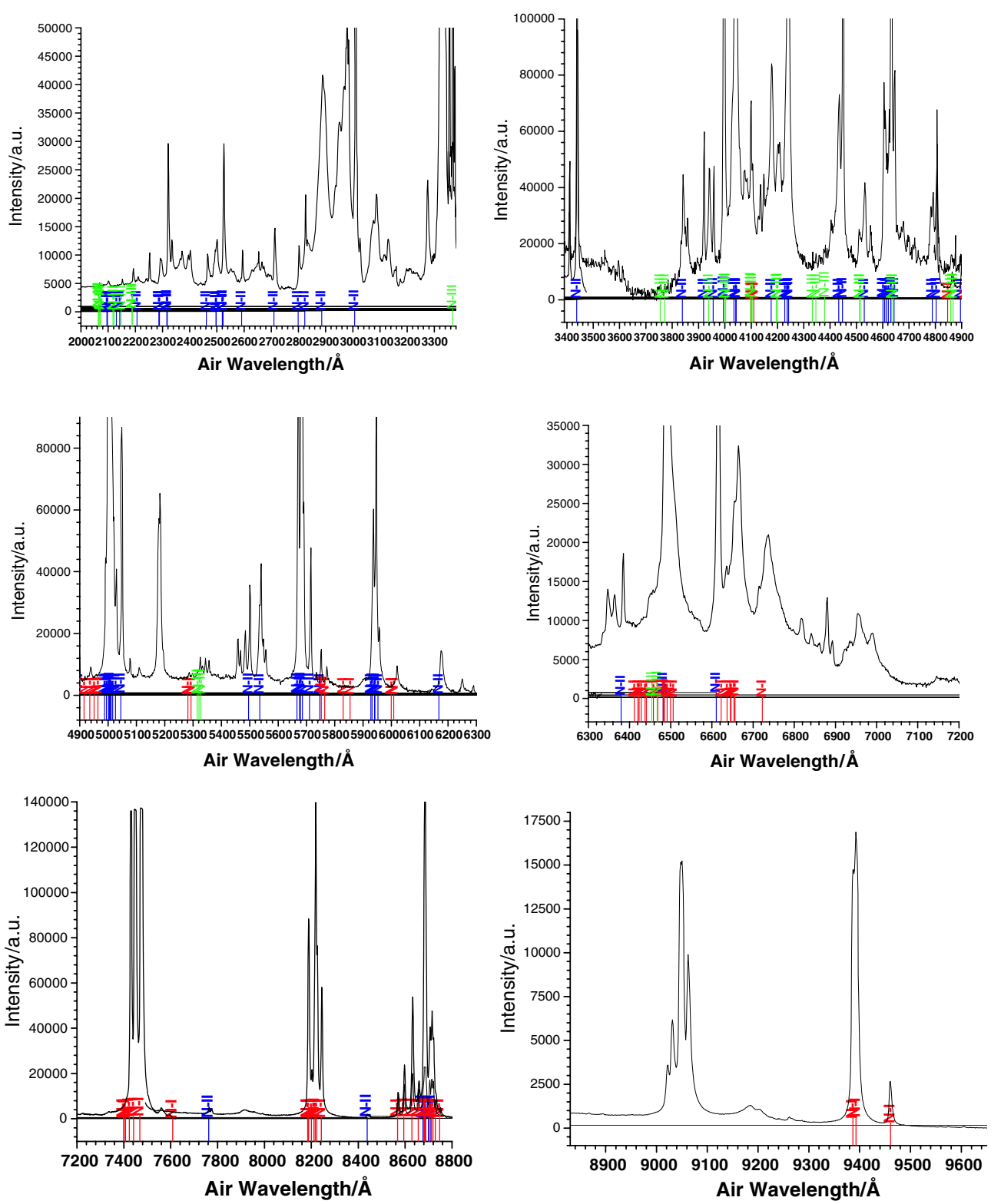

Figure 5. A zoom of the spectrum of figure 4.

$1 / 8 \mathrm{~m}$ Oriel spectrometer (1200 grooves $\mathrm{mm}^{-1}$ grating). A zoom of this spectrum is shown in figure 5. In this figure, in addition to the identified atomic lines, molecular bands associated with $\mathrm{N}_{2}^{+}$and $\mathrm{N}_{2}$ diatomic molecules are observed. The analysis of the molecular emission has already been used for a long time to get information on the structure and symmetry of excited states [31-34].

Studies of the electronic spectra of $\mathrm{N}_{2}$ and $\mathrm{N}_{2}^{+}$in a number of discharge tubes, such as electrodeless microwave discharges and conventional ac and dc discharges, are well known. In 
many electrical discharges, the most prominent electronic transitions of $\mathrm{N}_{2}$ are the first positive $\mathrm{B}^{3} \Pi_{\mathrm{g}}-\mathrm{A}^{3} \Sigma_{\mathrm{u}}^{+}$system (between 480 and $2530 \mathrm{~nm}$ ) and the second positive $\mathrm{C}^{3} \Pi_{\mathrm{u}}-\mathrm{B}^{3} \Pi_{\mathrm{g}}$ system (between 270 and $550 \mathrm{~nm}$ ) [6]. For the electronic states implied in the electronic transitions of $\mathrm{N}_{2}(\mathrm{C}-\mathrm{B}$ and $\mathrm{B}-\mathrm{A})$ and $\mathrm{N}_{2}^{+}(\mathrm{B}-\mathrm{X}$ and $\mathrm{D}-\mathrm{A})$, the vibrational quanta $\Delta G(v+1 / 2)$ in the upper and lower electronic states have similar magnitudes, and therefore the vibrational transitions with $\Delta v=v^{\prime}-v^{\prime \prime}$ constant (sequences) appear quite close. The known part of the $\mathrm{C}-\mathrm{B}$ second positive system of molecular nitrogen consists of the $\Delta v=4,3,2,1,0,-1,-2,-3,-4$, $-5,-6$ and -7 triple-headed band sequence, all degraded to the violet. A sharp cutting-off of the rotational in $v^{\prime}=4$ vibrational level of the $\mathrm{C}$ state is observed, which Herzberg [35] attributed to a predissociation. Pannetier et al [36] observed the 5-5 band of the C-B system with band-head at 3259.2 A. Also, Tanaka and Jursa [37] studied this band system with high intensity in the aurora afterglow observed for weak red-degraded triplet bands originate from $v^{\prime}=5\left(\mathrm{C}^{3} \Pi_{\mathrm{u}}\right)$. Perturbations of various types in the $\mathrm{C}^{3} \Pi_{\mathrm{u}}$ state of molecular nitrogen were also observed. Moreover, the most prominent electronic transitions of $\mathrm{N}_{2}^{+}$are the first negative $\mathrm{B}^{2} \Sigma_{\mathrm{u}}^{+}-\mathrm{X}^{2} \Sigma_{\mathrm{g}}^{+}$system (between 280 and $590 \mathrm{~nm}$ ) and the $\mathrm{A}^{2} \Pi_{\mathrm{u}}-\mathrm{X}^{2} \Sigma_{\mathrm{g}}^{+}$Meinel system (550 and $1770 \mathrm{~nm}$ ) [6]. The A-X Meinel bands for nitrogen cation were first identified in the aurora borealis [38]. The analysis of these band systems of $\mathrm{N}_{2}$ and $\mathrm{N}_{2}^{+}$was accomplished in the early work of many authors and played an important part in the development of our understanding of the spectra of diatomic molecules.

In order to assign the molecular features of the LIDB in nitrogen, its spectrum is compared to that of the dc electric glow discharge at low pressure ( $\sim 5$ Torr). Typical spectra recorded with the Oriel spectrometer (25 $\mu \mathrm{m}$ slit and grating of 1200 grooves $\mathrm{mm}^{-1}$ ) after $\mathrm{CO}_{2}$ laser excitation and in the cathode glow discharge of $\mathrm{N}_{2}$ are given in figure 6. A global analysis of the latter allows one to distinguish the second positive C-B system (between 270 and $530 \mathrm{~nm}$ ) and the first positive $\mathrm{B}-\mathrm{A}$ system (between 570 and $970 \mathrm{~nm}$ ) of $\mathrm{N}_{2}$ and very weak emissions corresponding to the first negative $\mathrm{B}-\mathrm{X}$ system of $\mathrm{N}_{2}^{+}$ions. Moreover, spectroscopic measurements performed on the dc electric glow in $\mathrm{N}_{2}$ spectrum showed that although numerous molecular bands appear, nitrogen atomic lines are not present. Besides, the second positive system of $\mathrm{N}_{2}$ and the first negative system of $\mathrm{N}_{2}^{+}$spectra are frequently observed simultaneously in plasma containing nitrogen. In the glow discharge in $\mathrm{N}_{2}$ at $5977.4 \AA$, the $0-0$ band of the $c_{4}{ }^{1} \Pi_{\mathrm{u}}-\mathrm{a}^{1} \Sigma_{\mathrm{g}}^{+}$Ledbetter Rydberg series [39] of nitrogen is observed overlapped with the 8-4 band sequence of the first positive B-A system. The LIDB emission spectrum of $\mathrm{N}_{2}$ (figure 6) shows six red-degraded heads in the region 225-275 nm which were readily assigned to the $\Delta v=0(v=0,1, \ldots, 6)$ band sequence of the $\mathrm{D}^{2} \Pi_{\mathrm{g}}-\mathrm{A}^{2} \Pi_{\mathrm{u}}$ Janin-d'Incan system [6] of $\mathrm{N}_{2}^{+}$. In the spectral range between 2700 and $5300 \AA$, the second positive system of $\mathrm{N}_{2}(\mathrm{C}-\mathrm{B})$ and the first negative system of $\mathrm{N}_{2}^{+}(\mathrm{B}-\mathrm{X})$ spectra are observed simultaneously. Table 1 lists the different molecular species that have been observed in the LIDB spectrum of nitrogen.

In order to investigate the different electronic bands of $\mathrm{N}_{2}$ and $\mathrm{N}_{2}^{+}$, both LIDB and highvoltage dc electric glow discharge spectra were recorded with a resolution of $\sim 0.12 \AA$ by a ISA Jobin Yvon Spex $0.32 \mathrm{~m}$ spectrometer. The high-resolution of the LIDB spectrum allowed us to resolve partially the vibrational bands of the second positive $\mathrm{C}-\mathrm{B}$ system of $\mathrm{N}_{2}$ and the first negative $\mathrm{B}-\mathrm{X}$ system of $\mathrm{N}_{2}^{+}$. Both spectra have been obtained with 40 successive exposures on the CCD camera in the spectral region 2000-7500 $\AA$. In the high-resolution spectra, no new processes were detected but allow us to identify unequivocally the band structure of the different transitions. As examples, figures 7(a)-(f) show a comparison between two spectra, the lower one obtained for the high-voltage dc electric discharge, and the upper one recorded in the LIDB experiment. We indicate with italic the position of the band-head $\left(v^{\prime}-v^{\prime \prime}\right)$ of first negative system of $\mathrm{N}_{2}^{+}(\mathrm{B}-\mathrm{X})$ while in regular typeface the bands of the second positive system 

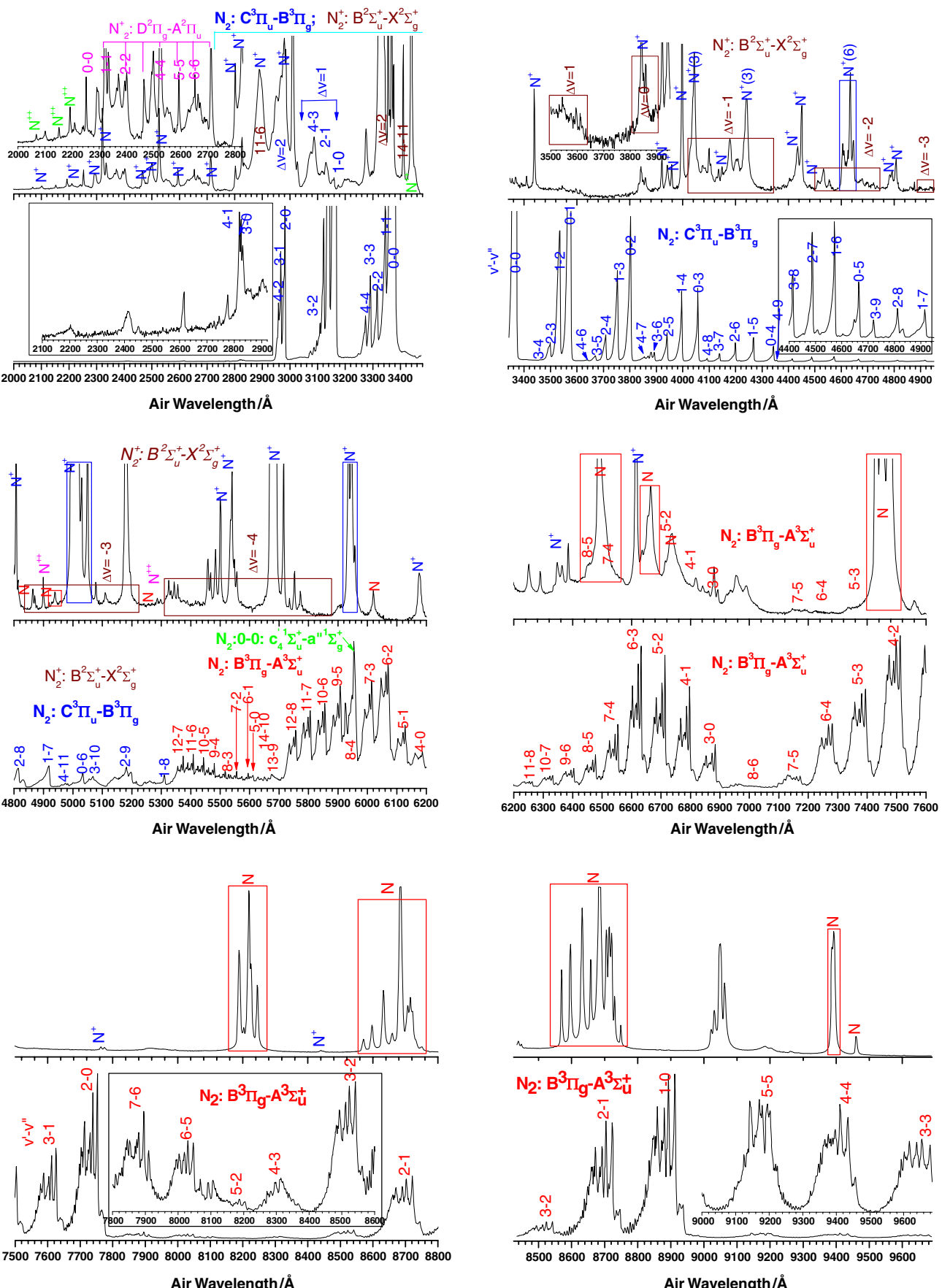

Air Wavelength/Å

Air Wavelength/Å

Figure 6. An overview of the low-resolution emission spectra observed in the 2000-9690 region. Upper panel: LIDB in nitrogen at a pressure of $1.2 \times 10^{5} \mathrm{~Pa}$, excited by the $9 \mathrm{P}(28)$ line at $1039.36 \mathrm{~cm}^{-1}$ of the $\mathrm{CO}_{2}$ laser; lower panel: dc electric glow discharge spectrum of nitrogen at low pressure. 
Table 1. List of the most intense observed molecular bands in the laser-induced dielectric breakdown in nitrogen, corresponding electronic transition and wavelength in $\AA$ (air) for the major band heads.

\begin{tabular}{|c|c|c|c|}
\hline Molecule & Name of the system & Observed band system & Major band heads $(\AA)\left(v^{\prime}, v^{\prime \prime}\right)$ \\
\hline $\mathrm{N}_{2}^{+}$ & Janin-d'Incan & $\mathrm{D}^{2} \Pi_{\mathrm{g}}-\mathrm{A}^{2} \Pi_{\mathrm{u}}$ & $\begin{array}{l}2343(0,0) ; 2398(1,1) ; 2456(2,2) ; 2516(3,3) ; \\
2579(4,4) ; 2645(5,5) ; 2714(6,6)\end{array}$ \\
\hline $\mathrm{N}_{2}^{+}$ & First negative & $\mathrm{B}^{2} \Sigma_{\mathrm{u}}^{+}-\mathrm{X}^{2} \Sigma_{\mathrm{g}}^{+}$ & $\begin{array}{l}2861.7(11,6) ; 3033.0(11,7) ; 3065.1(15,10) ; \\
3076.4(4,1) ; 3078.2(3,0) ; 3291.6(5,3) ; \\
3293.4(4,2) ; 3298.7(3,1) ; 3308.0(2,0) ; \\
3319.9(8,6) ; 3349.6(18,13) ; 3381.5(10,8) ; \\
3419.6(14,11) ; 3447.3(23,16) ; 3460.8(17,13) ; \\
3493.4(12,10) ; 3532.3(5,3) ; 3538.3(4,3) ; \\
3548.9(3,2) ; 3563.9(2,1) ; 3582.1(1,0) ; \\
3588.6(16,13) ; 3612.4(10,9) ; 3806.8(5,5) ; \\
3818.1(4,4) ; 3835.4(3,3) ; 3857.9(2,2) ; \\
3884.3(1,1) ; 3914.4(0,0) ; 4110.9(6,7) ; \\
4121.3(5,6) ; 4140.5(4,5) ; 4199.1(2,3) ; \\
4236.5(1,2) ; 4278.1(0,1) ; 4459.3(7,9) ; \\
4466.6(6,8) ; 4490.3(5,7) ; 4515.9(4,6) ; \\
4554.1(3,5) ; 4599.7(2,4) ; 4651.8(1,3) ; \\
4709.2(0,2) ; 4864.4(7,10) ; 4881.7(6,9) ; \\
4913.2(5,8) ; 4957.9(4,7) ; 5012.7(3,6) ; \\
5076.6(2,5) ; 5148.8(1,4) ; 5228.3(0,3) ; \\
5485.5(4,8) ; 5564.1(3,7) ; 5653.1(2,6) ; \\
5754.4(1,5) ; 5864.7(0,4)\end{array}$ \\
\hline $\mathrm{N}_{2}$ & Second positive & $\mathrm{C}^{3} \Pi_{\mathrm{u}}-\mathrm{B}^{3} \Pi_{\mathrm{g}}$ & $\begin{array}{l}2953.2(4,2) ; 2962.0(3,1) ; 2976.8(2,0) ; 3116.7 \\
(3,2) ; 3136.0(2,1) ; 3159.3(1,0) ; 3268.1(4,4) ; \\
3285.3(3,3) ; 3311.9(2,2) ; 3338.9(1,1) ; 3371.3 \\
(0,0) ; 3500.5(2,3) ; 3536.7(1,2) ; 3576.9(0,1) ; \\
3641.7(4,6) ; 3671.9(3,5) ; 3710.5(2,4) ; 3755.4 \\
(1,3) ; 3804.9(0,2) ; 3857.9(4,7) ; 3894.6(3,6) ; \\
3943.0(2,5) ; 3998.4(1,4) ; 4059.4(0,3) ; 4094.8 \\
(4,8) ; 4141.8(3,7) ; 4200.5(2,6) ; 4269.7(1,5) ; \\
4343.6(0,4) ; 4355.0(4,9) ; 4416.7(3,8) ; 4490.2 \\
(2,7) ; 4574.3(1,6) ; 4667.3(0,5) ; 4723.5(3,9) ; \\
4814.7(2,8) ; 4916.8(1,7) ; 5031.5(0,6) ; 5066.0 \\
(3,10) ; 5179.3(2,9) ; 5309.3(1,8)\end{array}$ \\
\hline $\mathrm{N}_{2}$ & First positive & $\mathrm{B}^{3} \Pi_{\mathrm{g}}-\mathrm{A}^{3} \Sigma_{\mathrm{u}}^{+}$ & $\begin{array}{l}6322.9(10,7) ; 6394.7(9,6) ; 6468.6(8,5) \\
6544.9(7,4) ; 6623.6(6,3) ; 6704.8(5,2) \\
6788.6(4,1) ; 6875.2(3,0) ; 7164.8(7,5)\end{array}$ \\
\hline
\end{tabular}

of $\mathrm{N}_{2}(\mathrm{C}-\mathrm{B})$. The upper panel of figure 7(a) shows the LIDB emission spectrum of nitrogen in the spectral region 2925-3175 $\AA$ of nitrogen. Assignment of the emission band heads is shown in table 1 and indicated also on the spectra. The two sets of three blue-degraded band heads (2925-2980 $\AA$ ) and (3105-3165 $\AA$ ) are readily assigned to the $\Delta v=2$ and $\Delta v=1$ sequences of the second positive system of $\mathrm{N}_{2}(\mathrm{C}-\mathrm{B})$, respectively. The series of bands between 3020 and $3095 \AA$ belong to any of the bands $11-7,4-1$ and 3-0 of the first negative system of $\mathrm{N}_{2}^{+}(\mathrm{B}-\mathrm{X})$. The lower panel, corresponding to the dc electric glow discharge of nitrogen at low pressure, shows practically the same bands with different intensity distributions and spectral widths. In the spectrum of the lower panel of figure 7(b) (nitrogen electric glow discharge), we easily identified five bands of the $\Delta v=0$ sequence and the $1-0$ band of the second positive system 
of $\mathrm{N}_{2}(\mathrm{C}-\mathrm{B})$. The main intensity is observed for the dominant transition $\mathrm{N}_{2}\left(\mathrm{C}, v^{\prime}=0\right) \rightarrow(\mathrm{B}$, $v^{\prime \prime}=0$ ) which corresponds to the most intense nitrogen laser line at $3371 \AA$. However, this simple picture changes drastically in the LIDB emission spectrum of nitrogen excited by the $\mathrm{CO}_{2}$ laser, the $0-0$ band being now very weak. A large number of additional strong bands mainly in the region 3260-3410 $\AA$ are detected in the LIDB spectrum and can be attributed to emissions from the first negative system of $\mathrm{N}_{2}^{+}$(especially for $\Delta v=2$ ). The $\mathrm{B}-\mathrm{X}$ system of $\mathrm{N}_{2}^{+}$has been observed over a wide range of vibrational levels. The highest values observed so far are $v^{\prime}=29$ for the excited B state and $v^{\prime \prime}=23$ for the $\mathrm{X}$ state. The main bands of this system lie in the $-2 \leqslant \Delta v \leqslant 2$ with $v^{\prime}<5$ sequences and all of these bands are blue degraded. However, under certain circumstances many more bands, some red degraded, are observed, most being tail bands of these sequences. The observed bands with $v^{\prime} \leqslant 7$ and also those with $8 \leqslant v^{\prime} \leqslant 11$ and $\Delta v<-1$ are shaded with violet. All the observed bands with $v^{\prime} \geqslant 12$ and those with $v^{\prime}=10$ and $11, \Delta v \geqslant 0$ are shaded with red although some bands appear headless. These bands are so-called tail bands taking place a reversal in the successions of the bands in the sequence. Moreover, in the bands of the first negative system of $\mathrm{N}_{2}^{+}$, numerous rotational line displacements and intensities anomalies arising from perturbations in the $\mathrm{B}$ state have been observed. The perturbing state is $A^{2} \Pi_{u}$. In the Deslandres table listing the observed band heads, there is a pronounced gap in one arm of the Condon locus, and a less marked one in the other [6]. Franck-Condon factors indicate that the missing bands should be as intense as many of the observed. The few bands observed in the region of the gap are 8-6 and 9-8 which are headless, and the 10-9 and 10-8 which have no definite heads. The missing bands coincide with the strong bands of either first negative system of $\mathrm{N}_{2}^{+}(\mathrm{B}-\mathrm{X})$ or the second positive system of $\mathrm{N}_{2}(\mathrm{C}-\mathrm{B})$, and are difficult to detect. In the spectrum of the lower panel of figure 7(c), corresponding to the nitrogen electric glow discharge we easily identified several bands of the $\Delta v=-1$ sequence and two weak 4-6 and 3-5 bands of the second positive system of $\mathrm{N}_{2}(\mathrm{C}-\mathrm{B})$. In this spectral region (3425-3675 $\AA$ ), the most intense bands are due to the transitions $\mathrm{N}_{2}\left(\mathrm{C}, v^{\prime}=0\right) \rightarrow\left(\mathrm{B}, v^{\prime \prime}=1\right)$ and $\mathrm{N}_{2}\left(\mathrm{C}, v^{\prime}=1\right) \rightarrow\left(\mathrm{B}, v^{\prime \prime}=2\right)$, also present in the LIDB emission spectrum of nitrogen in the upper panel of figure 7(c). As in the previous cases, the LIDB emission spectrum excited by the $\mathrm{CO}_{2}$ laser changes drastically regarding the emission spectrum of nitrogen electric glow discharge. In it a large number of additional strong bands corresponding mainly to the $\Delta v=+1$ sequence $\mathrm{B}-\mathrm{X}$ band system of $\mathrm{N}_{2}^{+}$are detected which are partially overlapped by the weak bands of the $\mathrm{C}-\mathrm{B}$ system of $\mathrm{N}_{2}$. For low $v^{\prime}$ the $1-0,2-1,3-2, \ldots$ bands of the $\mathrm{B}-\mathrm{X}$ system of $\mathrm{N}_{2}^{+}$are degraded to shorter wavelengths, and for high $v^{\prime}$ values the bands are degraded to longer wavelengths (tail bands). In the nitrogen electric glow discharge spectrum (lower panel of figure 7(d)), we identified $3-6,4-7,0-2,1-3$ and $2-4$ bands of the second positive system of $\mathrm{N}_{2}(\mathrm{C}-\mathrm{B})$ and $0-0,1-1$ and 2-2 bands of the first negative system of $\mathrm{N}_{2}^{+}$. In this spectral region (3675-3935 $\AA$ ), the most intense band is the $0-2$ band of $\mathrm{N}_{2}(\mathrm{C}-\mathrm{B})$. The LIDB emission spectrum in this region hardly shows bands of the second positive system of $\mathrm{N}_{2}(\mathrm{C}-\mathrm{B})$. However, this emission spectrum exhibits a large number of bands corresponding mainly to the $\Delta v=0$ sequence $\mathrm{B}-\mathrm{X}$ band system of $\mathrm{N}_{2}^{+}$.

In the spectra of the lower panel of figures 7(d)-(f) (nitrogen electric glow discharge), we identified several bands of the second positive system of $\mathrm{N}_{2}(\mathrm{C}-\mathrm{B})$, indicated on the spectra, and some very weak bands of the first negative system of $\mathrm{N}_{2}^{+}$. As in the previous cases, the spectra change drastically in the LIDB emission of nitrogen excited by the $\mathrm{CO}_{2}$ laser. A large number of $\mathrm{N}^{+}$and $\mathrm{N}^{2+}$ atomic lines and additional strong bands of the first negative system of $\mathrm{N}_{2}^{+}$are now present.

To understand the different processes involved in the analysed emission, Rydberg-KleinRees (RKR) potential energy curves for some bound electronic states of $\mathrm{N}_{2}$ and $\mathrm{N}_{2}^{+}$have 


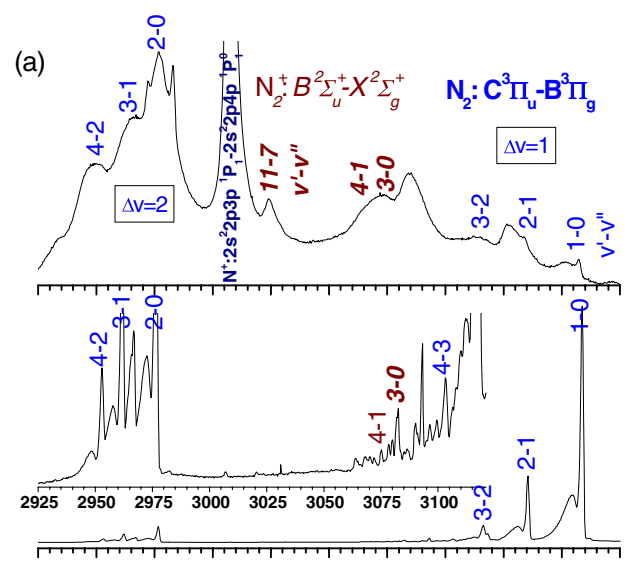

$29252950297530003025305030753100 \quad 312531503175$ Air Wavelength/Å

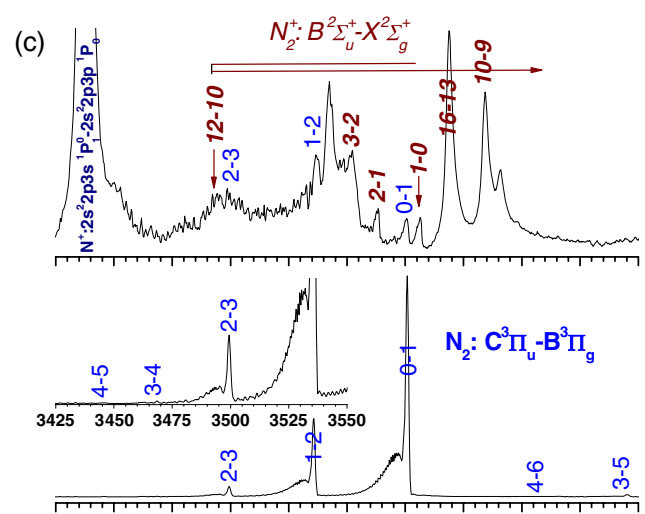

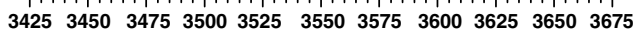
Air Wavelength/Å
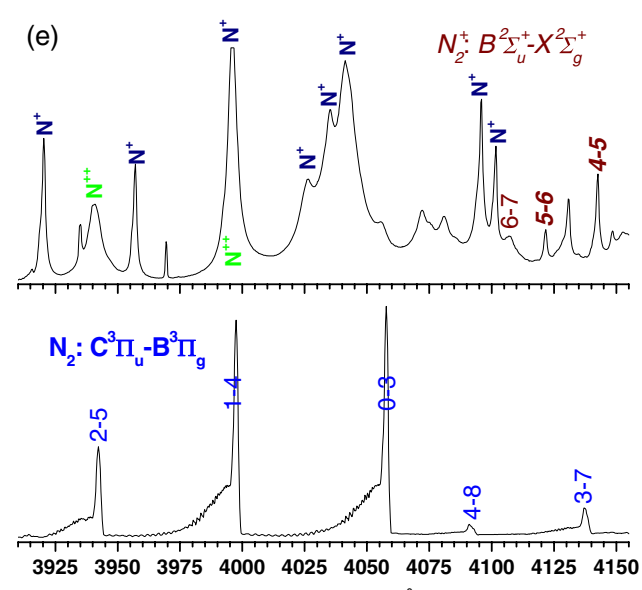

Air Wavelength/ $\AA$

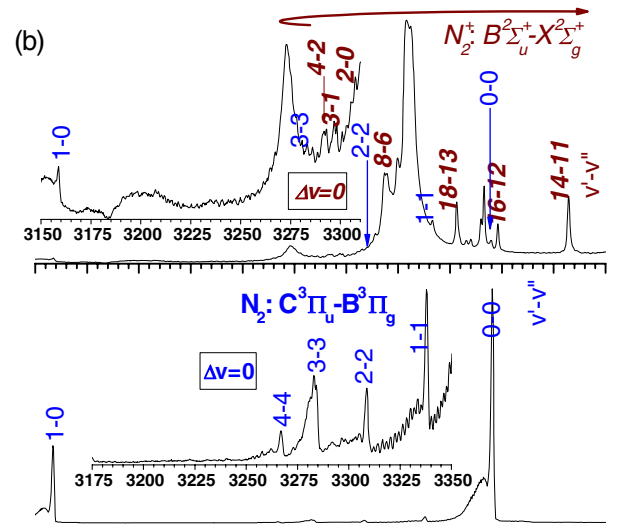

315031753200322532503275330033253350337534003425

Air Wavelength/
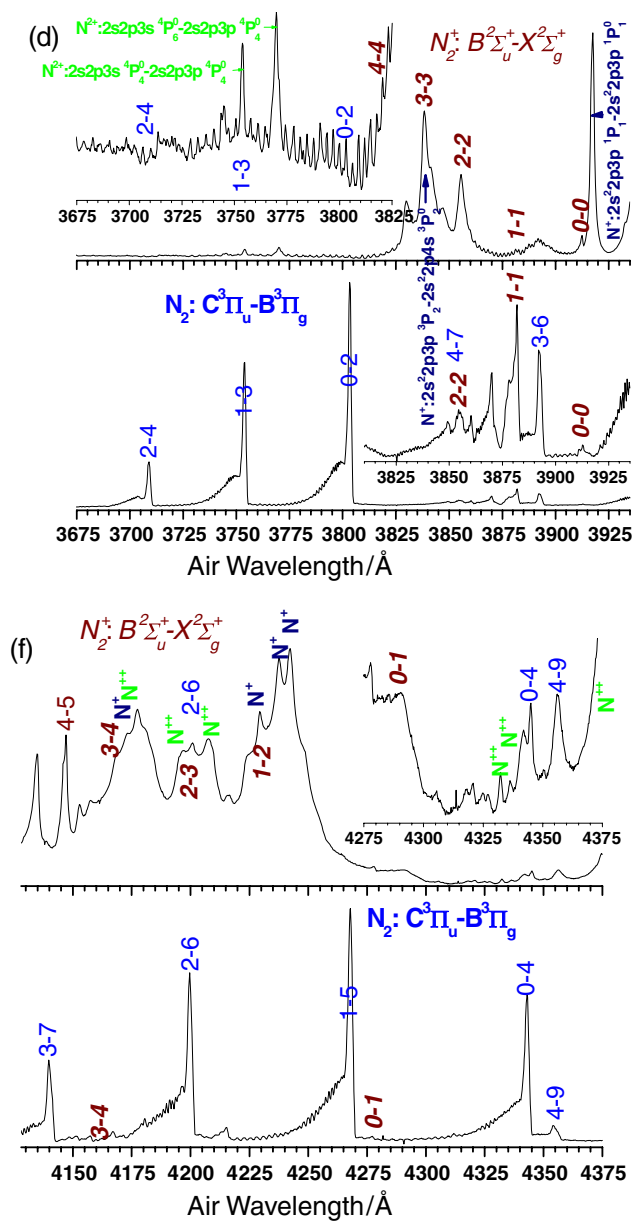

Figure 7. (a)-(f) Comparison between high-voltage dc electric discharge (lower panels) and LIDB (upper panels) emission spectra for nitrogen in several spectral regions. 


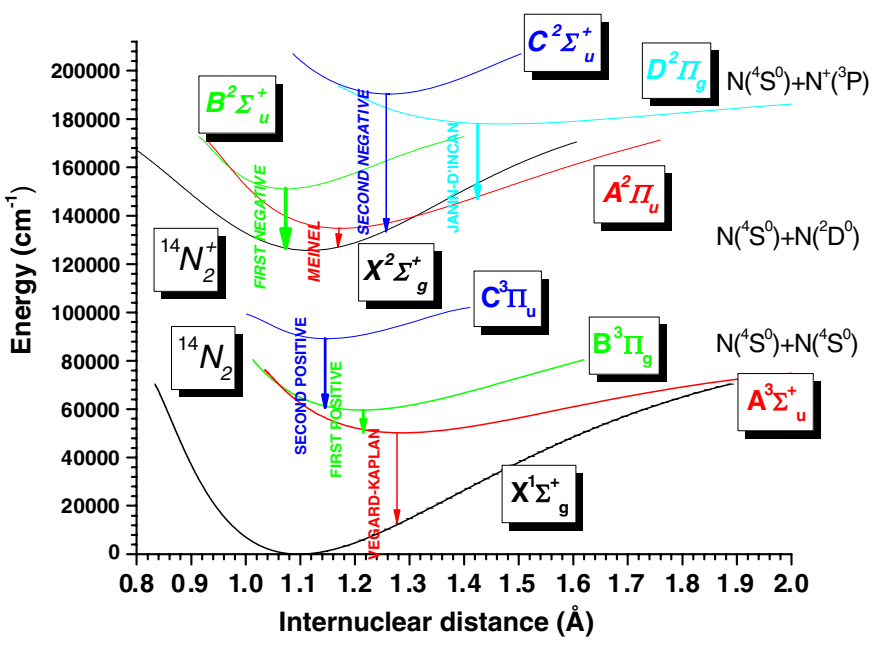

Figure 8. RKR potential energy curves for some bound electronic states of $\mathrm{N}_{2}$ and $\mathrm{N}_{2}^{+}$studied in this work.

been calculated. The potential energy curves for the $\mathrm{X}^{1} \Sigma_{\mathrm{g}}^{+}, \mathrm{A}^{3} \Sigma_{\mathrm{u}}^{+}, \mathrm{B}^{3} \Pi_{\mathrm{g}}, \mathrm{C}^{3} \Pi_{\mathrm{u}}$ states of $\mathrm{N}_{2}$ and $\mathrm{X}^{2} \Sigma_{\mathrm{g}}^{+}, \mathrm{A}^{2} \Pi_{\mathrm{u}}, \mathrm{B}^{2} \Sigma_{\mathrm{u}}^{+}, \mathrm{C}^{2} \Sigma_{\mathrm{u}}^{+}$and $\mathrm{D}^{2} \Pi_{\mathrm{g}}$ states of $\mathrm{N}_{2}^{+}$were obtained from the experimental information reported by Huber and Herzberg [40] and Laher and Gilmore [41]. Figure 8 shows the calculated RKR potentials and associated transitions for electronic states of $\mathrm{N}_{2}$ and $\mathrm{N}_{2}^{+}$which can be relevant to interpret the results of the present work. Many perturbations are known in molecular states of nitrogen, although an in-depth explanation of these features in terms of mixing of electronic states is not yet available. A useful graphical summary of many potential energy curves has been reported by Gilmore [42]. Perturbations are often accompanied by complex intensity irregularities as happens in the first negative system of $\mathrm{N}_{2}^{+}$. Whereas the vibrational and rotational constants run quite normal for the $\mathrm{X}^{2} \Sigma_{\mathrm{g}}^{+}$state of $\mathrm{N}_{2}^{+}$, this is not at all the case for the $\mathrm{B}^{2} \Sigma_{\mathrm{u}}^{+}$electronic state. Both the $B_{v}$ and $G(v)$ curves versus the vibrational quantum number $v$ have unusual shapes. This can be interpreted as caused by a strong mutual vibrational perturbation between the $\mathrm{B}^{2} \Sigma_{\mathrm{u}}^{+}$and $\mathrm{C}^{2} \Sigma_{\mathrm{u}}^{+}$states of the same species of $\mathrm{N}_{2}^{+}$(see figure 8 ). As this perturbation is homogeneous (i.e., $\Delta \Lambda=0$ ), the shifts in both levels will be nearly independent of $J$ producing that the $\mathrm{B}^{2} \Sigma_{\mathrm{u}}^{+}$potential curve to flatten out in the middle of its energy range. The minimum of the $\mathrm{C}^{2} \Sigma_{\mathrm{u}}^{+}$potential energy curve should be moved to smaller internuclear distances. There are also observed numerous rotational perturbations in the $\mathrm{B}-\mathrm{X}$ system of $\mathrm{N}_{2}^{+}$, caused by an interaction between the $\mathrm{A}^{2} \Pi_{\mathrm{u}}$ and the $\mathrm{B}^{2} \Sigma_{\mathrm{u}}^{+}$states.

\subsection{Ionization degree of the plasma}

When dielectric breakdown is produced in nitrogen under high intensity laser radiation, some molecules can obtain an energy that exceeds the binding energy. Also some of their electrons become so energetic that the atoms and molecules ionize. Taking into account our experimental spectral observations, at these high temperatures nitrogen becomes a mixture of $\mathrm{N}_{2}, \mathrm{~N}_{2}^{+}, \mathrm{N}$, $\mathrm{N}^{+}, \mathrm{N}^{2+}$ and electrons. The transition between a gas and a plasma is essentially a chemical equilibrium which shifts from gas to plasma side with increasing temperature. For example, if we assume a LTE between nitrogen atoms in the ground state $\mathrm{N}\left(1 \mathrm{~s}^{2} 2 \mathrm{~s}^{2} 2 \mathrm{p}^{3}:{ }^{4} S_{3 / 2}^{0}\right)$ and ionized 


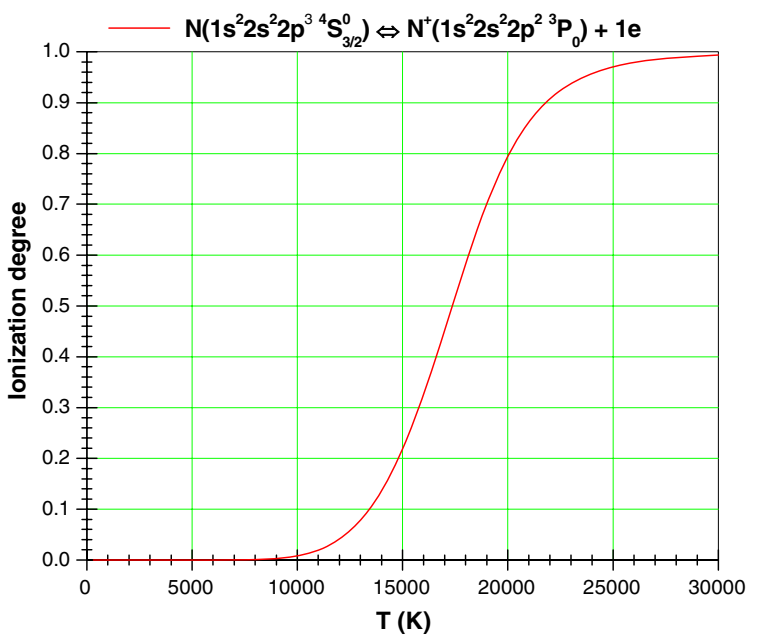

Figure 9. Temperature dependence of the ionization degree $N_{\mathrm{i}} /\left(N_{0}+N_{\mathrm{i}}\right)$ of atomic nitrogen at a constant pressure of $1.2 \times 10^{5} \mathrm{~Pa}$.

nitrogen atoms $\mathrm{N}^{+}\left(1 \mathrm{~s}^{2} 2 \mathrm{~s}^{2} 2 \mathrm{p}^{2}:{ }^{3} P_{0}\right)$ at temperature $T$, the ionization degree is described by the Saha equation:

$$
\frac{N_{\mathrm{e}} \times N_{\mathrm{i}}}{N_{0}}=\frac{g_{\mathrm{e}} \times g_{\mathrm{i}}}{g_{0}} \frac{\left(2 \pi m_{\mathrm{e}} k_{B} T\right)^{3 / 2}}{h^{3}} \mathrm{e}^{-E_{\mathrm{i}} / k_{B} T},
$$

where $N_{\mathrm{e}}=N_{\mathrm{i}}$ are the electron and ion densities, $N_{0}$ is the density of the neutrals, $h$ is Planck's constant, $k_{B}$ is Boltzmann's constant, $m_{\mathrm{e}}$ is the electron mass, $g_{\mathrm{e}}, g_{\mathrm{i}}$ and $g_{0}$ are the statistical weights of the electrons $\left(g_{\mathrm{e}}=2\right), \mathrm{N}^{+}$ions $\left(g_{\mathrm{i}}=1\right), \mathrm{N}$ neutrals $\left(g_{0}=4\right)$ and $E_{\mathrm{i}}$ is the ionization energy. For atomic nitrogen, the Saha equation reads $\left(E_{\mathrm{i}}=14.5341 \mathrm{eV}[43]\right)$

$$
\frac{N_{\mathrm{e}} \times N_{\mathrm{i}}}{N_{0}}=1.20734 \times 10^{21} T^{3 / 2} \mathrm{e}^{-E_{\mathrm{i}} / k_{B} T},
$$

where $T$ is in $\mathrm{K}$ and $N_{\mathrm{e}} \times N_{\mathrm{i}} / N_{0}$ is in $\mathrm{m}^{-3}$. Figure 9 shows the ionization degree $N_{\mathrm{i}} /\left(N_{0}+N_{\mathrm{i}}\right)$ of nitrogen gas, plotted as a function of the gas temperature $T$ at a constant total pressure $P=\left(N_{0}+N_{\mathrm{e}}+N_{\mathrm{i}}\right) k_{B} T$ of $1.2 \times 10^{5} \mathrm{~Pa}$. The graph shows that the nitrogen is already fully ionized at thermal energies well below the ionization energy of $14.5341 \mathrm{eV}$ (equivalent to $168661 \mathrm{~K})$. From our experiments, it is obtained that at about 1/8 of the ionization energy (equivalent to IR 14 photons), the majority of the nitrogen atoms are ionized (ionization degree 0.87). The situation for the hypothetical equilibrium $\mathrm{N}_{2}\left(\mathrm{X}^{1} \Sigma_{\mathrm{g}}^{+}\right) \leftrightarrow \mathrm{N}_{2}^{+}\left(\mathrm{X}^{2} \Sigma_{\mathrm{g}}^{+}\right)+$e is quite similar. Already at lower temperatures the electrically charged components of a partially ionized nitrogen gas can dominate the behaviour of the gas.

\subsection{Plasma temperature measurement}

We have calculated the excitation temperature $T_{\text {exc }}$ according to the Boltzmann equation under the assumption of LTE. The conditions satisfying this assumption of LTE require that the radiative population rates are negligible compared to the collisional population rates. This essentially implies that an excited state must have a higher probability of de-excitation by collision than by spontaneous emission. Generally, LTE is established among all the species in the plasma beyond $\sim 1 \mu$ s delay time from the plasma start. The excitation temperature was 


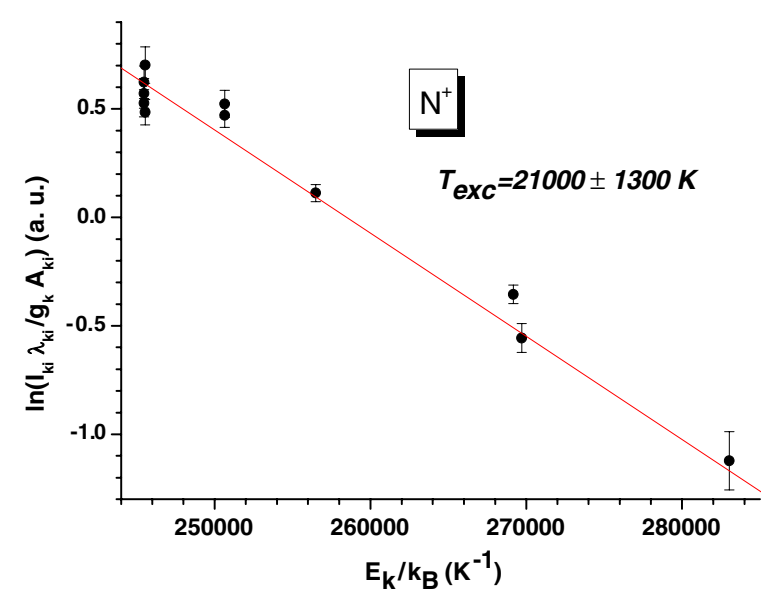

Figure 10. Linear Boltzmann plot for several $\mathrm{N}^{+}$transition lines used to calculate plasma temperature, $T_{\text {exc }}$. The plot also shows a linear fit to the data with a regression coefficient of $R^{2} \sim 0.91$.

calculated from the relative intensities of $\mathrm{N}^{+}$atomic lines (3400-4800 $\AA$ spectral region) and the slope of the Boltzmann plot $\ln \left[I_{k i} \times \lambda_{k i} / g_{k} \times A_{k i}\right]$ versus $E_{k} / k_{B}$ :

$$
\ln \left[\frac{I_{k i} \times \lambda_{k i}}{g_{k} \times A_{k i}}\right]=C-\frac{E_{k}}{k_{B} \times T_{\mathrm{exc}}},
$$

where $I_{k i}$ is the emissivity in $\mathrm{W} \mathrm{m}^{-3} \mathrm{sr}^{-1}$ of the emitted $k \rightarrow i$ spectral line, $\lambda_{k i}$ is the wavelength, $g_{k}=2 J_{k}+1$ is the statistical weight, $A_{k i}$ is the Einstein transition probability of spontaneous emission, $E_{k} / k_{B}$ is the normalized energy of the upper electronic level and $C=\ln \left(h c N_{k} / 4 \pi Q(T)\right)\left(Q(T)\right.$ is the partition function). The values of $\lambda_{k i}, g_{k}, A_{k i}$ and $E_{k}$ for $\mathrm{N}^{+}$selected atomic lines were obtained from the NIST Atomic Spectral Database [24-30]. The obtained excitation temperature, in this case, was $T_{\mathrm{exc}}=21000 \pm 1300 \mathrm{~K}$ (figure 10). However, if the excitation temperature is determined using only the relative intensities of $\mathrm{N}$ atomic lines (7300-8800 $\AA$ spectral region), a value of $T_{\mathrm{exc}}=7900 \pm 1300 \mathrm{~K}$ is obtained. This behaviour is observed by other authors [44] and may be interpreted to result from the different emissivity distributions of neutral atoms and ion lines. The emissivity of the ion lines is produced, on the average, near the inner region with higher temperature. On the contrary, the emissivity of the neutral atom lines comes, on average, from the low-temperature region close to the plasma front, where the neutral atom density is higher. The intensity measurements correspond to the integration of the local emissivity values along the line-ofsight, integrated in turn in the perpendicular directions. As a consequence, the neutral atom Boltzmann plot provides a temperature value which is a certain average of the low-temperature values in the plasma $(7900 \mathrm{~K})$, whereas the temperature obtained from the ion Boltzmann plot $(21000 \mathrm{~K})$ averages the values existing in the high-temperature region. On the other hand, we have carried out simulations of the $\Delta v=+1$ sequence of $\mathrm{B}-\mathrm{X}$ band of $\mathrm{N}_{2}^{+}$for different vibrational temperatures finding that a value around $20000 \mathrm{~K}$ reasonably reproduces the experimental spectrum. Also, if we consider a temperature of $7900 \mathrm{~K}$ the ionization degree obtained by means of the Saha equation (2) is of 0.00064 (see figure 9). Such a low ionization degree does not justify the observed emission spectra of $\mathrm{N}^{+}$and $\mathrm{N}_{2}^{+}$. Keeping in mind these results, the temperature obtained from relative intensity of $\mathrm{N}^{+}$atomic lines $(21000 \pm$ $1300 \mathrm{~K}$ ) was chosen as the first approximation for the excitation temperature. Real plasmas 
provide, even in the worst cases, just an approximation to LTE. However, their spatial inhomogeneity is very large as concerns the temperature and number density distributions of the different species. Consequently, the LTE occurs only within very small volume of the plasma.

\subsection{Laser-induced breakdown mechanism in nitrogen}

It is clear that the LIDB and glow discharge spectra are remarkably different. The lack of correlation between the LIDB spectrum generated by the $\mathrm{CO}_{2}$ laser pulses in nitrogen and the molecular emission spectrum formed in a glow discharge suggests that the relaxation from excited states of nitrogen and nitrogen cation during the LIDB plasma emission occurs through other pathways. The strong atomic lines observed in the LIDB spectra in comparison with the dc glow discharge spectra, as well as the similarities between the LIDB spectra and those obtained using synchrotron radiation [12], indicate the high degree of excitation and the high rate of the $\mathrm{N}_{2}$ dissociation process achieved in the plasma. As we have mentioned, the two most important processes involving the formation of laser-induced plasma are MPI and electron cascade or IB. While the multiphoton ionization process is self-sufficient, the electron cascade requires the presence of at least one electron in the laser focal region. The MPI process involves the simultaneous absorption of a number of photons required to equal the ionization potential of a gas. Due to the small energy of the laser photons $(h v=0.128864 \mathrm{eV})$ and the ionization potential of nitrogen $(15.5807 \mathrm{eV} \mathrm{[6]),} \mathrm{the} \mathrm{usual} \mathrm{photoelectric} \mathrm{effect} \mathrm{is} \mathrm{not} \mathrm{possible.}$ Multiphoton ionization process would be possible if a simultaneous absorption of 121 photons would occur. In general, the probability $w_{n}$ of a species absorbing simultaneously $n$ photons when in the field $E$ ( $E$ is the root-mean-square electric field, i.e., the amplitude of the field oscillations $E=\sqrt{2} E_{0}$ ) corresponding to a photon flux density $F$ ( $F=J$ (power density in $\left.\mathrm{W} \mathrm{cm}^{-2}\right) / h v$ photons $\left.\mathrm{cm}^{-2} \mathrm{~s}\right)$ is $w_{n} \propto F^{n} \propto E^{2 n}$. As it can be seen, the dependence on the laser field is very sharp. Bebb and Gold $[45,46]$ concluded that although multiphoton ionization may supply the initial electrons, it does not account entirely for the breakdown phenomenon, except possibly at very low pressures when the formation of an electron cascade is inhibited. Moreover, it has been established [45, 46] that the threshold photon flux density $F_{\text {th }}$ or equivalently the threshold power density $J_{\text {th }}$ for multiphoton ionization varies with $P^{-1 / n}$, where $P$ is the gas pressure and $n$ is the number of simultaneously absorbed photons. Therefore, MPI predicts a very weak dependence of $J_{\text {th }}$ on $P$ for nitrogen. However, as we can see from figure 3 , the breakdown threshold power density $J_{\text {th }}$ in $\mathrm{N}_{2}$ versus pressure shows a minimum around $5 \times 10^{4} \mathrm{~Pa}$ if previous breakdown have existed and $1 \times 10^{5} \mathrm{~Pa}$ without previous breakdown. Therefore, it can be seen from figure 3 that the pressure dependence is incompatible with MPI which predicts a very weak $P^{-1 / n}$ dependence for the threshold power density, while it is in qualitative agreement with electron cascade. Moreover, Rosen and Weyl [21] reported a $P^{-0.6}$ scaling $(0.2<P<10$ atm $)$ of threshold laser power density $J_{\text {th }}$ for $\mathrm{N}_{2}$ at 0.53 and $0.35 \mu \mathrm{m}$, indicating that this behaviour is associated with electron cascade rather than MPI. A minimum in the variation of the threshold power density versus pressure is predicted by the classical theory $[47,48]$. In our experiments, a minimum in the threshold power density versus pressure curve (figure 3 ) is observed. The electron cascade process can also starts with an initial number of electrons in the focal volume that are produced by natural ionization due to cosmic radiation [49]. In air at atmospheric pressure, the natural electron density is $\sim 10^{3} \mathrm{~cm}^{-3}$. Therefore, starting from our experimental observations we can conclude that although, the first electrons must appear via multiphoton ionization or natural ionization, electron cascade is the main mechanism responsible for the breakdown in $\mathrm{N}_{2}$. 


\section{Conclusions}

Laser-induced dielectric breakdown generated by $\mathrm{CO}_{2}$ laser pulses in nitrogen gas has been investigated by means of OES. The plasma produced in nitrogen gas and pressures ranging from $4 \times 10^{3}$ to $1.2 \times 10^{5} \mathrm{~Pa}$ has been measured and analysed. Optical breakdown threshold intensities in $\mathrm{N}_{2}$ at $9.621 \mu \mathrm{m}$ have been measured. The strong emission observed in the plasma region is mainly due to the relaxation of excited atomic $\mathrm{N}$ and ionic fragments $\mathrm{N}^{+}$and $\mathrm{N}^{2+}$. Various atomic lines overlap with molecular features of $N_{2}^{+}\left(B^{2} \Sigma_{u}^{+}-X^{2} \Sigma_{g}^{+}\right), N_{2}^{+}\left(D^{2} \Pi_{g}-A^{2} \Pi_{u}\right)$, $\mathrm{N}_{2}\left(\mathrm{C}^{3} \Pi_{\mathrm{u}}-\mathrm{B}^{3} \Pi_{\mathrm{g}}\right)$ and $\mathrm{N}_{2}\left(\mathrm{~B}_{3} \Pi_{\mathrm{g}}-\mathrm{A}^{3} \Sigma_{\mathrm{u}}^{+}\right)$transitions and produce a rather complex structure, but the high-resolution spectra allow for a precise assignment of many observed transitions. In LIDB spectra, the relative intensities of the $0-0$ band heads in the $\mathrm{N}_{2}(\mathrm{C}-\mathrm{B})$ and $\mathrm{N}_{2}^{+}(\mathrm{B}-\mathrm{X})$ systems are surprisingly very weak. The LIDB spectrum has been compared with the band spectrum of a dc electric glow discharge at low pressure. This spectrum is dominated by the emission of strong molecular features $\mathrm{N}_{2}(\mathrm{C}-\mathrm{B})$ and $\mathrm{N}_{2}(\mathrm{~B}-\mathrm{A})$ and very weak $\mathrm{N}_{2}^{+}(\mathrm{B}-\mathrm{X})$. Both spectra exhibit very big differences associated with the involved different excitation mechanisms. An excitation temperature around $21000 \mathrm{~K}$ was calculated by means of ionized nitrogen atomic lines assuming LTE. This value implies an ionization degree that agrees with the observed LIDB emission spectra. The physical processes leading to the LIDB of nitrogen in the power density range $0.4<J<4.5 \mathrm{GW} \mathrm{cm}^{-2}$ have been analysed. On the basis of our experimental observations, we can suggest that although the first electrons must appear via multiphoton ionization or natural ionization, electron cascade is the main mechanism responsible for the breakdown in nitrogen.

\section{Acknowledgments}

It is a pleasure to acknowledge the excellent technical support of A Magro. We gratefully acknowledge the support received from the DGICYT (Spain) Projects I+D: BQU2002-01502 and MEC: CTQ2007-60177/BQU for this research.

\section{References}

[1] Isenor N R and Richardson M C 1971 Appl. Phys. Lett. 18224

[2] Lyman J L and Jensen R J 1972 Chem. Phys. Lett. 13421

[3] Cantrell C D, Freund S M and Lyman J L 1979 Laser Induced Chemical Reactions and Isotope Separation in Laser Handbook vol 3b ed M L Stitch (Amsterdam: North-Holland)

[4] Lyman J L, Quigley G P and Judd O P 1980 Multiple-Photon Excitation and Dissociation of Polyatomic Molecules ed C D Cantrell (Berlin: Springer)

[5] Hermann J and Floch T L 2004 J. Appl. Phys. 963084

[6] Lofthus A and Krupenie P H 1977 J. Phys. Chem. Ref. Data 6113

[7] Babankova D et al 2006 J. Phys. Chem. A 11012113

[8] Nordstrom R J 1995 Appl. Spectrosc. 491490

[9] Hanafi M, Omar M M and Gamal Y E E D 2000 Radiat. Phys. Chem. 1157

[10] Baravian G, Godart J and Sultan G 1982 Phys. Rev. A 251483

[11] Sorokin A A, Bobashev S V, Tiedke K and Richter M 2006 J. Phys. B: At. Mol. Opt. Phys. 39299

[12] Marquette A, Gisselbrecht M, Benten W and Meyer M 2000 Phys. Rev. A 6222513

[13] D'Orazio M and Schrader B 1974 J. Raman Spectrosc. 2585

[14] Reader J, Sansonetti C J and Bridges J M 1996 Appl. Opt. 3578

[15] Chan C H, Moody C D and McKnight W K 1973 J. Appl. Phys. 441179

[16] Chan C H and Moody C D 1974 J. Appl. Phys. 451105

[17] Gamal Y E E-D and Abdel-Monelm N M 1987 J. Phys. D: Appl. Phys. 20757

[18] Kroll N and Watson K M 1972 Phys. Rev. A 51883

[19] Gamal Y E E-D and Azzouz I M 2001 J. Phys. D: Appl. Phys. 343243 
[20] Smith D C 1971 Appl. Phys. Lett. 19405

[21] Rosen D I and Weyl G 1987 J. Phys. D: Appl. Phys. 201264

[22] Striker J and Parker J G 1982 J. Appl. Phys. 53851

[23] Gasmi T, Zeaiter H A, Ropero G and González-Ureña A 2000 Appl. Phys. B 71169

[24] NIST Atomic Spectra Database http://physics.nist.gov/PhysRefData/ASD/index.html

[25] Eriksson K B S 1983 Phys. Scr. 28593

[26] Moore C E 1975 Natl Stand. Ref. Data Ser., Natl Bur. Stand. (U.S.) vol 3 section 5

[27] Brown J M, Varberg T D, Evenson K and Cooksy A L 1994 Astrophys. J. 428 L37

[28] Spyromilio J 1995 Mon. Not. R. Astron. Soc. 277 L59

[29] Wiese W L, Fuhr J R and Deters T M 1996 J. Phys. Chem. Ref. Data Monogr. 7335

[30] Morton D C 2003 Astrophys. J. Suppl. Ser. 149205

[31] Herzberg G 1950 Spectra of Diatomic Molecules (New York: Van Nostrand)

[32] Gaydon A G 1968 Dissociation Energies and Spectra of Diatomic Molecules (London: Chapman and Hall)

[33] Steinfeld J I 1986 An Introduction to Modern Molecular Spectroscopy (London: MIT Press)

[34] Bernath P F 1995 Spectra of Atoms and Molecules (New York: Oxford University Press)

[35] Herzberg G 1931 Ergeb. Exakten Nat.wiss. 10207

[36] Pannetier G, Marsigny G L and Guenebaut H C 1961 R. Acad. Sci., Paris 2521753

[37] Tanaka Y and Jursa A S 1961 J. Opt. Soc. Am. 511239

[38] Meinel A B 1950 Astrophys. J. 112562

[39] Ledbetter J W Jr 1972 J. Mol. Spectrosc. 42100

[40] Huber K P and Herzberg G 1979 Molecular Spectra an Molecular Structure: IV. Constants of Diatomic Molecules (New York: Van Nostrand-Reinhold)

[41] Laher R R and Gilmore F R 1991 J. Phys. Chem. Ref. Data 20685

[42] Gilmore F R 1965 J. Quant. Spectrosc. Radiat. Transfer 5369

[43] Eriksson K B S and Pettersson J E 1971 Phys. Scr. 3211

[44] Aguilera J A and Aragon C 2004 Spectrochim. Acta B 591861

[45] Bebb H B and Gold A 1966 Multiphoton ionization of hydrogen and rare gas atoms Physics of Quantum Electronics ed P L Kelly, B Lax and P E Tannenwald (New York: McGraw-Hill)

[46] Bebb H B and Gold A 1966 Phys. Rev. 1431

[47] Zel'dovich Y B and Raiser Y P 1965 Sov. Phys._JETP 21190

[48] Demichelis C 1969 IEEE J. Quantum Electron. 5188

[49] Kopiczynski T L, Bogdan M, Kalin A W, Schotzau H J and Kneubuhl F K 1992 Appl. Phys. B: Photophys. Laser Chem. $\mathbf{5 4} 526$ 